УДК $338: 378.14$

$10.17213 / 2075-2067-2020-4-83-90$

\title{
ИННОВАЦИОННЫЙ МЕНЕДЖМЕНТ В МЕДИАПРОСТРАНСТВЕ
}

\author{
(C) 2020 г. В. Г. Ларионов*, Е. Н. Шереметьева **, Л. А. Горикова *** \\ *Московский государственный технический университет \\ имени Н. Э. Баумана, г. Москва, Россия \\ **Самарский государственный экономический университет, г. Самара, Россия \\ ***Самарский национальный исследовательский университет \\ имени академика С. П. Королева, г. Самара, Россия
}

Целью исследования является анализ особенностей инновачионного менеджмента в медиапространстве. Мультимедийная среда приходит на замену традиционным СМИ, которые теряют свою актуальность на рынке информации. Глобальным инновационным процессом, протекающим в медиапространстве, является конвергенция.

Методологическую базу исследования представляют сравнительный анализ, контент-анализ, методы дедукиии и моделирования как метод научного познания социально-экономических прочессов. Исследование базируется на идеях одного из разработчиков теории медиаконвергенции Г. Дженкинса, на теоретических представлениях о медиаменеджменте А. В. Вырковского и многих других.

Результаты исследования. Раскрыты аспекты управления конвергентной редакиией СМИ, ее специфические особенности. Инновационный менеджмент в медиапространстве инициировал появление не только новых организационных структур СМИ, но и формирование новых методов подачи информачии (инфотейнмент, финишинг, «беседка», глокализация, бильдизачия). Показана роль инновационного менеджмента в формировании массовых информачионных предпочтений, иенностей аудитории, новых методов подачи информации.

Перспективу исследования составляет формирование медиапространства и «новых медиа», отличительной чертой которых является интерактивность и использование передовых компьютерных технологий, направленных на превращчение пассивных потребителей информации в активных, формирование новых организаџионных структур СМИ и управление ими.

Ключевые слова: коммуникация; медиапространство; инновационный менеджмент; медиасреда; конвергенция; конвергентная редакция СМИ; медиапродукт.

\section{INNOVATIVE MANAGEMENT IN THE MEDIA SPACE}

\author{
(C) 2020 V. G. Larionov*, E. N. Sheremetyeva**, L. A. Gorshkova*** \\ *Bauman Moscow State Technical University, Moscow, Russia \\ **Samara State University of Economics, Samara, Russia \\ ***Samara National Research University named after academician S. P. Korolev, \\ Samara, Russia
}

The purpose of the study is to analyze the features of innovative management in the media space. The multimedia environment is replacing traditional media, which are losing their relevance 
in the information market. Convergence is a global innovation process that takes place in the media space.

The methodological base of the study is represented by comparative analysis, methods of cognition, content analysis, methods of deduction and modeling as a method of scientific knowledge of socio-economic processes. The research is based on the ideas of one of the developers of the theory of media convergence, G. Jenkins, on the theoretical concepts of media management, A.V. Vyrkovsky and many others.

The results of the study. Aspects of managing converged media editorial staff and its specific features are revealed. Innovative management in the media space has initiated the emergence of not only new organizational structures of the media, but also the formation of new methods of presenting information (infotainment, finishing, «arbor», glocalization, bildization). The role of innovation management in the formation of mass information preferences, audience values, and new methods of information presentation is shown.

The prospect of the study is the formation of media and new media, the hallmark of which is the interactivity and the use of advanced computer technologies aimed at turning passive consumers of information to active, the formation of new organizational structures, media and management.

Key words: communication; media space; innovative management; media environment; convergence; converged media; media product.

Введение. В результате ускоренного развития средств коммуникации в конце XX начале XXI века происходит изменение процессов получения и обмена информацией и формирование медиапространства. Современное медиапространство является частью информационного пространства и представлено печатными и электронными СМИ. Медиапространство превращается в глобальную среду обитания человека, охватывающую все сферы его жизнедеятельности [2].

Медиапространство понимается как часть социального пространства, используя которое, оно осуществляет презентацию самого себя [14] с помощью СМИ, потоков информации, каналов коммуникации, различных технических систем передачи информации.

Инновационный менеджмент во взаимосвязи с медиапространством можно определить как совокупность принципов и методов, инструментов управления инновационными процессами в медиапространстве во всем их многообразии.

Среди глобальных инноваций медиапространства необходимо выделить построение совершенно новой медиасреды, отвечающей современным процессам глобализации ин- формационного пространства, и формирование инновационного типа управления медиасредой.

Глобальным инновационным процессом, протекающим в медиапространстве, является конвергенция.

Конвергенция представляет собой процесс формирования новых организационных СМИ, ставших результатом слияния нескольких различных по типу и направленности СМИ: радио, телевидения, печатных СМИ, Интернет-изданий, новостных платформ социальных сетей и др. [7].

Цель конвергенции СМИ - создание цифрового медиапродукта [6] с помощью мультимедийных технологий, способного объединить текстовые, визуальные и аудиовизуальные элементы информационного пространства для расширения потребительской аудитории.

Среди предпосылок конвергенции СМИ можно отметить: снижение спроса на печатную продукцию (особенно новостного типа); ускоренный темп жизни, формирующий у аудитории потребность в получении обновляемой информации; «клиповое мышление»; интерес к получению новостей через привычные контенты в сети Интернет. 
Еще одним существенным шагом к конвергенции СМИ стала замена классификационного названия медиа. СМИ трансформируются в средства массовой коммуникации (CMK).

Мультимедийная среда приходит на замену традиционных СМИ, которые теряют свою актуальность на рынке информации.

Предпосылки создания нового типа редакционной управленческой политики. По словам одного из разработчиков теории медиаконвергенции Г. Дженкинса, изменение спроса аудитории на виды информации и способы их получения привело к тому, что руководители СМИ были вынуждены перевести свои издания на контенты, которые привычны потребительской аудитории [1]. Например, печатные СМИ создали электронные контенты своих изданий, оплачивают трафик в сети Интернет и приобретают информационное пространство (ниши) для публикации не только своих новостей, но и иного рода публикаций в социальных сетях, сторонних сайтах. Поиск руководителями и издателями СМИ доступных для потребителей контентов привел к тому, что стал формироваться новый тип редакционной управленческой политики.

Новая редакционная управленческая политика стала ориентироваться на мобильность в получении и трансляции информации с привлечением всех доступных технических средств и инноваций.

Конвергенция СМИ привела к тому, что формируется интегрированная подача новостей на различных информационных платформах, которая требует объединения специалистов в единую команду и создания организационной структуры нового типа.

Инновационный менеджмент в медиапространстве в свою очередь направлен на формирование новых организационных структур СМИ и управление ими, обеспечение их эффективного функционирования как экономического и социального института [5].

Инновационные методы подачи информации. Упрощенно можно рассматривать инновационный менеджмент в медиапространстве как управление медиапредприятием с использованием современных технологий.
Инновационный менеджмент в медиапространстве инициировал появление не только новых организационных структур СМИ, но и формирование новых методов подачи информации, среди которых можно выделить:

— инфотейнмент (передача информации в формате развлечения);

- финишинг (трансляция информационного продукта, доведенного до логического завершения);

- «беседка» (обмен информацией в неформальном и дружеском формате на базе СМИ, в том числе и в режиме онлайн);

- глокализация (смещение глобальных проблем и их привязка к локальной проблематике сообщества);

- бильдизация (красочная подача информации) и др. [10].

Указанные методы подачи информации могут быть использованы на различных технологических платформах СМИ. Учитывая существующий кризис чтения [14], инновационные методы подачи информации способны создавать доступные для любых категорий граждан визуальные и аудиоконтенты.

Востребованными и интересными для аудитории становятся новые жанры журналистики, транслирующие тексты в режиме онлайн: онлайн-конференция, онлайн-репортаж, твиттер-репортаж, онлайн-дневник, журналистский блог [13].

Следующий аспект инновационного менеджмента связан с формированием массовых предпочтений, стереотипов, создания необходимых моделей поведения, ценностей [4]. Данные категории формируются с помощью содержательного компонента мультимедийного продукта (содержательного смысла), методов подачи информации и расширенного применения технологических средств подачи (дизайн, графика, звук, скетчинг, комиксы, слайд-шоу, лонгрид и т.п.) [9].

Взаимодействие новых типов СМИ и культурного пространства в эпоху глобализации способствуют появлению новых типов культуры и культурного мышления.

С одной стороны, современные технологии управления медиапространством способны структурировать систему духовно-нравственных ценностей, важных для государства, общества и личности, создавая на платфор- 
мах СМИ познавательные, просветительские, религиозные контенты и каналы.

С другой стороны, новые СМИ зачастую превращаются в механизм манипуляции обществом и общественным сознанием, навязывая ему определенные стереотипы, образ мышления, псевдоценности, размывая национальную идентификацию.

СМИ, транслируя аудитории информацию, претендуют на ее объективность и предоставляют возможность обмена мнениями. Обмен мнениями приводит к дальнейшему распространению информации, что влияет на трансформацию реальности в сознании своих собеседников. Негативным следствием такого процесса является манипулирование сознанием общественности, что может угрожать стабильности и безопасности государства.

Итогом использования управленческих инноваций становится формирование медиапространства и «новых медиа», отличительной чертой которых является интерактивность [8] и использование передовых компьютерных технологий, направленных на превращение пассивных потребителей информации в активных.

Целевая аудитория в медиаменеджменте рассматривается как составная часть равноправного диалога с конвергентными СМИ, а журналистика в эпоху цифровых коммуникаций превращается в «журналистику соучастия» [3].

Конвергентная редакция СМИ. В управлении конвергентными СМИ основной акцент делается на достижение и реализацию таких характеристик новых медиа, как мультимедийность, открытость, вовлекающий характер, модульность.

Новая организационная структура СМИ получила название «конвергентная редакция СМИ».

Конвергентная редакция СМИ определяется как мобильная, производственно-творческая организационная структура, создающая медиапродукт для различных видов СМИ, входящих в структуру медиаобъединения, и реализующая обмен информацией между ними [12].

Конвергентная редакция СМИ включает в себя следующие структурные элементы.

1. «Мультимедийный» круглый стол (SuperDesk), являющийся ядром конверген- тной редакции СМИ. «Мультимедийный» круглый стол обеспечивает оперативную подачу новостей, разработку их содержания различными специалистами. В состав «мультимедийного» круглого стола входят редакторы всех СМИ, интегрированных в конвергентную редакцию, арт-директора, продюсеры, редакторы пользовательских контентов и другие специалисты.

При появлении информационного повода все специалисты совместно разрабатывают мультимедийный продукт для различных видов СМИ одновременно и принимают коллективное решение по его трансляции [11].

При формировании конвергентной редакции СМИ и «мультимедийного» круглого стола центром деятельности выступает не медийный продукт, а потребительская аудитория, на которую он ориентируется. СМИ передает свои доминирующие позиции в разработке информационного материала потребителю, ориентируясь на его запросы.

«Мультимедийный» круглый стол является своеобразным мозговым центром конвергентной редакции и контролирует два крупных управленческих процесса: по созданию мультимедийного продукта и по управлению человеческими ресурсами.

2. Контент-группы. Специалисты, ведущие работу с различными аудиториями. Контент-группы получают задание для разработки содержания новости, поиска, сбора и обработки дополнительной информации от специалистов «мультимедийного» круглого стола.

3. Тематические редакции (отделы). Специалисты тематических редакций отвечают за содержание новостного продукта в соответствии с его направленностью (например, спортивной, культурной, политической, религиозной и т.п.) и технологическую сторону подачи (например, разработка иконографики для печатного издания, видеоряда для подачи новости на визуальных информационных платформах).

Создание нового типа управления конвергентной редакцией СМИ привело к тому, что появилась необходимость в репортерах нового типа, обладающего на профессиональном уровне различными техниками работы с информационными материалами. Редакторы, работающие с текстами, стали утрачивать 
свою значимость. В штате стали появляться редакторы, способные не только писать тексты, но и снимать видеосюжеты, фотографировать, монтировать ролики, уметь отбирать полезный и релевантный материал в различных источниках.

Управленческой инновацией в работе тематических редакций является привлечение широкого спектра удалённых специалистов, интернет-блогеров. Подобный подход помогает экономить затраты на персонал, привлекая на временной основе отдельных специалистов, способных создать информационный продукт, который необходим в конкретное время и конкретной аудитории.

Управление конвергентной редакцией СМИ сосредоточено в руках директора, peaлизующего общее руководство. В то время как специалисты «мультимедийного» круглого стола действуют совместно в рамках единого ньюзрума (комнаты новостей) [12], делегируя часть полномочий специалистам контентгрупп и тематических редакций (отделов).

Взаимодействие всех структурных подразделений конвергентной редакции СМИ обеспечивает максимальный охват аудитории и оперативную передачу информации.

Основными качественными характеристиками эффективности управления конвергентной редакцией СМИ выступают охват аудитории медиатекстом или мультимедийным продуктом и коэффициент вовлеченности.

Охват представляет собой то количество людей, которое имело контакт с мультимедийным продуктом хотя бы один раз.

Коэффициент вовлеченности определяется как процент активных читателей, используемый для оценки попадания мультимедийного продукта в целевую аудиторию.

Таким образом, инновационный менеджмент в медиапространстве направлен на формирование нового типа коммуникации в современном обществе, обладающего такими характеристиками, как мобильность, конвергенция и интерактивность.

Управление конвергенцией СМИ в медиапространстве ориентировано на создание медиареальности с активным вовлечением в нее пользователей информации, которые благодаря современным технологиям трансляции медиапродуктов включаются в процесс его генерации.
Заключение. Проведенный нами анализ медиапространства в условиях совершенствования медиасреды, отвечающей современным процессам глобализации информационного пространства, позволяет сформировать инновационный тип управления медиасредой. Глобальным инновационным процессом, протекающим в медиапространстве, является конвергенция. Нами были определены аспекты управления конвергентной редакцией СМИ, ее специфические особенности.

Инновационный менеджмент в медиапространстве инициировал появление не только новых организационных структур СМИ, но и формирование новых методов подачи информации (инфотейнмент, финишинг, «беседка», глокализация, бильдизация). Показана роль инновационного менеджмента в формировании массовых информационных предпочтений, ценностей целевой аудитории, новых методов подачи информации. Отличительной чертой «новых медиа» является интерактивность и использование передовых компьютерных технологий, направленных на превращение пассивных потребителей информации в активных. Управленческой инновацией в работе тематических редакций является привлечение широкого спектра удалённых специалистов, интернет-блогеров.

Следовательно, мобильность, конвергенция и интерактивность - новые типы коммуникации в современном обществе, а инновационный менеджмент в медиапространстве - это новые форматы управления медиапредприятием с использованием современных технологий.

\section{Литература}

1. Афанасов Н.Б. Генри Дженкинс и фанфик по теории медиа // Галактика медиа: журнал медиаисследований. - 2019. - №3. C. 250-263.

2. Водопьян В.Г. Медиапространство в сфеpe массовой коммуникации: социокультурная реальность // Вестник Адыгейского государственного университета. - 2017. №1 (194). - С. 182-189.

3. Волкова И. И., Гужвий Д.А. Интегративный подход к измерению эффективности контента в новых медиа: постановка пробле- 
мы // Вестник РУДН. Серия: Литературоведение. Журналистика. - 2017. - Т. 22. №3. - С. 532-543.

4. Володенков C. В. От информации к коммуникации: коммуникационные технологии в условиях современного пост-информационного общества [Электронный ресурс]// Вестник Московского государственного областного университета. - 2016. - №4. Режим доступа: https://elibrary.ru/download/ elibrary_27811176_88337685.pdf. (Дата обращения: 22.01 .2020 г.).

5. Вырковский А.В. Теоретические представления о медиаменеджменте: основные подходы и проблемные зоны // Вопросы теории и практики журналистики. - 2016. T. 5. - №1. - C. 29-44.

6. Вырковский А. В., Галкина М. Ю. Феномен конвергенции с точки зрения участников процесса создания медиапродукта // Век информации. - 2017. - №2. - С. 146-147.

7. Головкова И.А. Процессы конвергенции в современных СМИ // Сборник материалов XIII Всероссийской молодёжной научнопрактической конференции «Молодежные исследования и инициативы в науке, образовании, культуре, политике». - Биробиджан, 2018. - С. 70-76.

8. Давлетшина С.Р. «Новые медиа» и тенденции развития мультимедийных жанров // Научный вестник Воронежского государственного архитектурно-строительного университета. Серия «Лингвистика и межкультурная коммуникация». - 2017. №2 (25). - С. 86-92.

9. Жумаш Ж. М. Использование новых медиа для повышения лояльности аудитории// Медиасреда. - 2019. - №1. - С. 25-32.

10. Марков А.А., Молчанова О.И., Полякова Н. В. Теория и практика массовой информации: учебник / Под общ. ред. А. А. Маркова. - М.: ИНФРА-М, 2017. — 252 с.

11. Мелешевич Р.И. Конвергенция в медиасреде: к вопросу определения понятия // Труды БГТУ. — 2019. - №1. - C. 83-88.

12. Молчанова О.И. Конвергентная редакция как новый тип организации редакционной структуры СМИ // Знание. Понимание. Умение. - 2018. - №1. - С. 157-166.

13. Молчанова О.И. Понятие и субъекты системы обеспечения управления процессами формирования конвергентных массме- диа // Вестник Поволжского института управления. - 2017. - №4. - С. 111-118.

14. Плахтий И.С. Развитие медиапространства в современном обществе [Электронный ресурс] // Молодой ученый. 2017. - №17. - С. 204-207. - Режим доступа: https://moluch.ru/archive/151/42922/. (Дата обращения: 24.01.2020 г.).

\section{References}

1. Afanasov N.B. Genri Dzhenkins i fanfik po teorii media [Henry Jenkins and fan fiction on media theory] // Galaktika media: zhurnal mediaissledovanij [Galaxy of media: journal of media research]. — 2019. — №3. - Pp. 250-263.

2. Vodop'jan V.G. Mediaprostranstvo v sfere massovoj kommunikacii: sociokul'turnaja real'nost' [Media space in the sphere of mass communication: socio-cultural reality] // Vestnik Adygejskogo gosudarstvennogo universiteta [Bulletin of the Adygeya State University]. 2017. - №1 (194). - Pp. 182-189.

3. Volkova I. I., Guzhvij D.A. Integrativnyj podhod $\mathrm{k}$ izmereniju jeffektivnosti kontenta $\mathrm{v}$ novyh media: postanovka problemy [An integrative approach to measuring the effectiveness of content in new media: statement of the problem]// Vestnik RUDN. Serija: Literaturovedenie. Zhurnalistika [Vestnik RUDN. Series: Literary Studies. Journalism]. - 2017. — Vol. 22. — №3. - Pp. 532-543.

4. Volodenkov S. V. Ot informacii k kommunikacii: kommunikacionnye tehnologii $\mathrm{v}$ uslovijah sovremennogo post-informacionnogo obshhestva [From information to communication: communication technologies in the conditions of modern post-information society] [Jelektronnyj resurs] // Vestnik Moskovskogo gosudarstvennogo oblastnogo universiteta [Bulletin of the Moscow State Regional University]. 2016. — №4. — URL: https://elibrary.ru/download/ elibrary_27811176_88337685.pdf. (Date accessed: 22.01 .2020 ).

5. Vyrkovskij A.V. Teoreticheskie predstavlenija o mediamenedzhmente: osnovnye podhody i problemnye zony [Theoretical concepts of media management: main approaches and problem areas] // Voprosy teorii i praktiki zhurnalistiki [Questions of journalism theory and practice]. 2016. - Vol. 5. — №1. - Pp. 29-44.

6. Vyrkovskij A.V., Galkina M. Ju. Fenomen konvergencii s tochki zrenija uchastnikov proc- 
essa sozdanija mediaprodukta [The phenomenon of convergence from the point of view of participants in the process of creating a media product]// Vek informacii [Information age]. 2017. — №2. - Pp. 146-147.

7. Golovkova I.A. Processy konvergencii v sovremennyh SMI [The process of convergence in the modern media] // Sbornik materialov XIIIVserossijskoj molodjozhnoj nauchno-prakticheskoj konferencii «Molodezhnye issledovanija i iniciativy $v$ nauke, obrazovanii, kul'ture, politike» [Collection of materials of the XIII allRussian youth scientific and practical conference "Youth research and initiatives in science, education, culture, and politics»)]. - Birobidzhan, 2018. - Pp. 70-76.

8. Davletshina S.R. «Novye media» i tendencii razvitija mul'timedijnyh zhanrov [ «New media» and trends in the development of multimedia genres] // Nauchnyj vestnik Voronezhskogo gosudarstvennogo arhitekturnostroitel'nogo universiteta. Serija «Lingvistika i mezhkul'turnaja kommunikacija» [Scientific Bulletin of the Voronezh State University of Architecture and Construction. Series «Linguistics and intercultural communication»]. - 2017. №2 (25). - Pp. 86-92.

9. Zhumash Zh. M. Ispol'zovanie novyh media dlja povyshenija lojal'nosti auditorii [Using new media to increase audience loyalty] // Mediasreda [The media environment]. - 2019. №1. - Pp. 25-32.
10. Markov A.A., Molchanova O.I., Poljakova N. V. Teorija i praktika massovoj informacii: uchebnik [Theory and practice of mass media: textbook] / In A.A. Markov (eds.). - Moscow: INFRA-M, 2017. - $252 \mathrm{p}$.

11. Meleshevich R.I. Konvergencija v mediasrede: $\mathrm{k}$ voprosu opredelenija ponjatija [Convergence in the media environment: on the issue of defining the concept] // Trudy BGTU [Works of BSTU]. - 2019. - №1. - Pp. 83-88.

12. Molchanova O.I. Konvergentnaja redakcija kak novyj tip organizacii redakcionnoj struktury SMI [Convergent editorial Board as a new type of organization of the media editorial structure] // Znanie. Ponimanie. Umenie [Knowledge. Understanding. Skill]. — 2018. — №1. — Pp. 157-166.

13. Molchanova O.I. Ponjatie i subekty sistemy obespechenija upravlenija processami formirovanija konvergentnyh massmedia [The concept and subjects of the system of providing management of the processes of formation of convergent mass media] // Vestnik Povolzhskogo instituta upravlenija [Bulletin of the Volga Region Institute of Management]. — 2017. №4. - Pp. 111-118.

14. Plahtij I. S. Razvitie mediaprostranstva $\mathrm{v}$ sovremennom obshhestve [Development of media space in modern society] [Jelektronnyj resurs] // Molodoj uchenyj [Young scientist]. 2017. — №17. — Pp. 204-207. — URL: https:// moluch.ru/archive/151/42922/. (Date accessed: 24.01.2020).

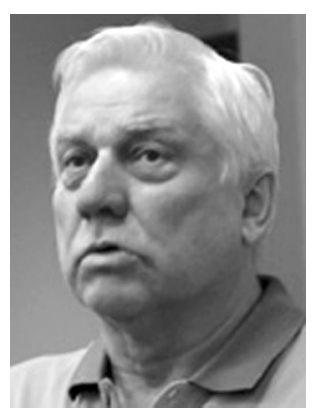

Ларионов Валерий Глебович - доктор экономических наук, профессор кафедры «Экономика и организация производства» Московского государственного технического университета имени Н.Э. Баумана, профессор. Специалист в области стратегического инновационного менеджмента.

Larionov Valerij Glebovich - Doctor of Economic Science, Professor of Department «Economics and Industrial Engineering», Bauman Moscow State Technical University. Specialist in the field of strategic innovation management.

105005, Москва, 2-я Бауманская ул., 5, стр. 1

5 2nd Baumanskaya st., bld. 1, 105005, Moscow, Russia

E-mail: bauman@bmstu.ru 

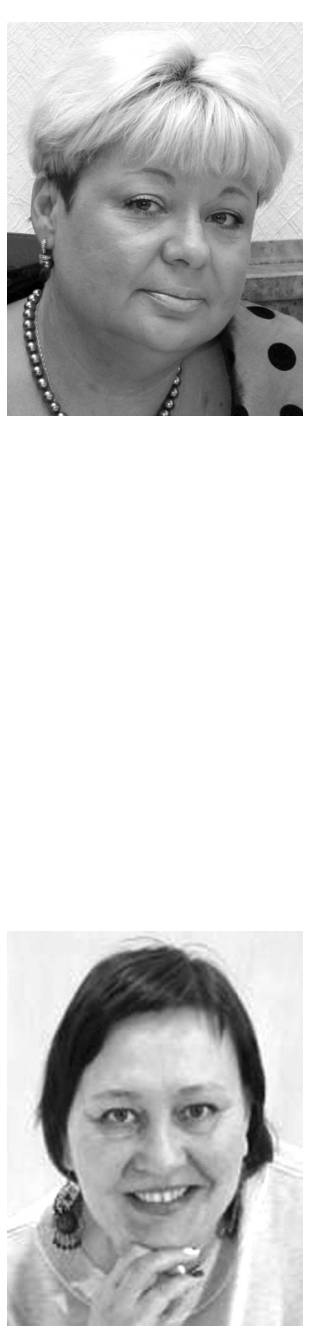

Шереметьева Елена Николаевна - доктор экономических наук, профессор кафедры экономической теории Самарского государственного экономического университета, доцент. Специалист в области цифровой экономики, инновационного менеджмента и маркетинга.

Sheremetyeva Elena Nickolaevna - Doctor of Economic Science, Professor of Department of Economic Theory, Samara State Economic University. Specialist in the field of digital economy, innovation management and marketing.

443090, г. Самара, ул. Советской Армии, 141

141 Soviet Army st., 443090, Samara, Russia

E-mail: lena_scher@mail.ru

Горшкова Лариса Анатольевна - кандидат филологических наук, доцент кафедры теории и истории журналистики, доцент Самарского национального исследовательского университета имени академика С.П. Королева. Специалист в области русской и зарубежной филологии, журналистики.

Gorshkova Larisa Anatolyevna - Candidate of Philological Sciences, Associate Professor of the Department of Theory and History of Journalism, Associate Professor, Samara National Research University named after academician S. P. Korolev. Specialist in the field of Russian and foreign philology, journalism.

443093, г. Самара, ул. Мориса Тореза, 10, кв. 88

10 Maurice Toreza st., app. 88, 443093, Samara, Russia

E-mail: gorshkova_lar@mail.ru 